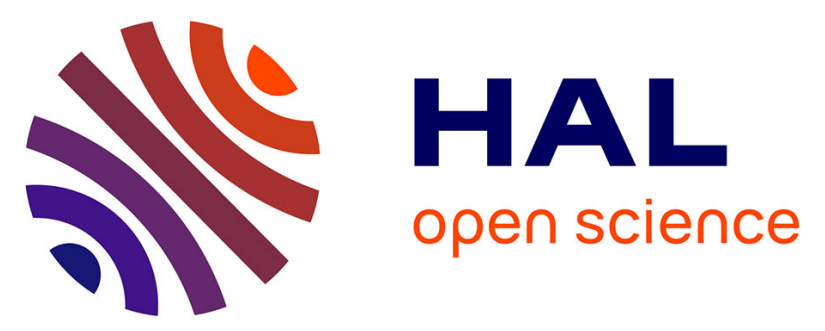

\title{
Study of the impact of DC-DC converters on the protection strategy of HVDC grids
}

J.D. D Páez, J. Maneiro, D. Frey, S. Bacha, A. Bertinato, Piotr Dworakowski

\section{To cite this version:}

J.D. D Páez, J. Maneiro, D. Frey, S. Bacha, A. Bertinato, et al.. Study of the impact of DC-DC converters on the protection strategy of HVDC grids. 15th IET International Conference on AC and DC Power Transmission (ACDC 2019), Feb 2019, Coventry, United Kingdom. 29 (6 pp.)-29 (6 pp.), 10.1049/cp.2019.0029 . hal-03303128

\section{HAL Id: hal-03303128 \\ https://hal.science/hal-03303128}

Submitted on 28 Jul 2021

HAL is a multi-disciplinary open access archive for the deposit and dissemination of scientific research documents, whether they are published or not. The documents may come from teaching and research institutions in France or abroad, or from public or private research centers.
L'archive ouverte pluridisciplinaire HAL, est destinée au dépôt et à la diffusion de documents scientifiques de niveau recherche, publiés ou non, émanant des établissements d'enseignement et de recherche français ou étrangers, des laboratoires publics ou privés. 


\title{
Study of the impact of DC-DC converters on the protection strategy of HVDC grids
}

\author{
J. D. Páez $z^{\dagger}$, J. Maneiro ${ }^{\dagger}$, D. Frey ${ }^{*}+$, S. Bacha ${ }^{*}+$ A. Bertinato ${ }^{\dagger}$, and P. Dworakowski ${ }^{\dagger}$ \\ ${ }^{+}$SuperGrid Institute, France, Contact: juan.paez@supergrid-institute.com, ${ }^{*}$ Univ. Grenoble Alpes, CNRS, Grenoble INP*, \\ G2Elab, 38000 Grenoble, France
}

Keywords: HVDC, DC-DC converters, DC grid protection, multi-terminal DC grid.

\begin{abstract}
HVDC grids are expected to be a solution to upgrade the existing AC system. However, their development presents several technical challenges like power flow control, grid protection and interconnection of grids with different technology or voltage levels. One required technology for the development of such grids is the DC-DC converter capable of operating at hundreds of kilovolts and hundreds of megawatts. While different DC-DC converter topologies have been proposed in literature, most studies focus on the topology itself and there is a lack of studies that deal with their grid integration. This paper studies the role of DC-DC converters in the protection of HVDC grids acting as firewalls to stop the propagation of faults. The effects of blocking the converter or actively controlling its operation during faults are presented. The results demonstrate the capabilities of DC-DC converters beyond DC voltage transformation.
\end{abstract}

\section{Introduction}

HVDC grids have been recently proposed as a future expansion of current electrical grids. They can offer flexibility and help with the integration of large scale renewable energy sources. The development of such grids is likely to be done in several steps, first interconnecting the existing HVDC Point-to-Point (P2P) lines to form local grids and then by their interconnection to evolve into larger grids [1].

Given the differences existing in each P2P link due to the lack of an HVDC standard, DC-DC converters acting as interface elements will be necessary. They can interconnect grids with different voltage levels, technology (LCC-VSC) and architectures (monopolar-bipolar). These circuits offer different features like power flow control, DC voltage regulation and fault blocking capability. This last characteristic is of high interest for the protection of the grid.

Indeed, one of the technical challenges to implement HVDC grids is the protection during faults, given the low impedance of DC lines that causes a fast propagation of faults and the difficulties associated to interrupt a DC fault current.

This topic is being highly researched nowadays and several protection strategies have been proposed [2]. One of them consists in partitioning the grid in protection zones or sub-grids using fast DC circuit breakers (DCCB) or DC-DC converters with fault blocking capability. In the event of a fault, the faulted zone is isolated quickly from the rest of the system avoiding the fault propagation and the loss of the whole grid.

Most DC-DC converter topologies that have been proposed in literature for HVDC have the capability of blocking DC faults [3]. Consequently, they can be used as firewalls in a partitioned grid scenario. Some examples of grid partitioning using these circuits can be found in [4]-[6].

In [4], [6] the converter is blocked when the fault is detected, stopping the fault propagation but generating a voltage dip on the healthy sub-grid caused by the power flow interruption. In [5] it is proposed to keep the converter unblocked during faults to recover the power flow from the healthy lines of the faulty zone as fast as possible. However the proposed method requires fast isolation of faults using fast DCCBs and inductors for current gradient limitation in addition to the DC-DC converter.

In this paper the study of the partition of an HVDC grid into two protection zones using a DC-DC converter is presented. A converter based on the Front-to-Front (F2F) Modular Multilevel Converter (MMC) [7] is considered. A converter control method is proposed to mitigate the perturbation on the healthy grid during faults, blocking only the converter side on the faulty sub-grid while keeping the healthy side unblocked and controlled. This method is compared with the approach used in [4] where the converter is totally blocked. The proposed method is independent of the protection strategy of each protection zone, so no DCCB or inductors at the end of each line are required for the converter operation compared to the proposal in [5].

\section{Case Study}

\subsection{System configuration}

The adopted case study is the interconnection of two P2P HVDC links as shown in Figure 1. Their interconnection with a DC-DC converter creates a radial four-terminal HVDC grid with two sub-grids (each P2P link) with different voltage levels. Each terminal includes a MMC interconnected to an ideal $\mathrm{AC}$ grid, i.e. a three phase $\mathrm{AC}$ voltage source with a series impedance.

The first sub-grid (Grid 1) is an asymmetrical monopole of $+640 \mathrm{kV}$ composed by two stations (MMC1 and MMC2) interconnected by cables $\mathrm{C} 1$ and $\mathrm{C} 2$. In the node $\mathrm{N}$ between both cables two mechanical DC breakers, CB1 and CB2, are

* Institute of Engineering Univ. Grenoble Alpes 


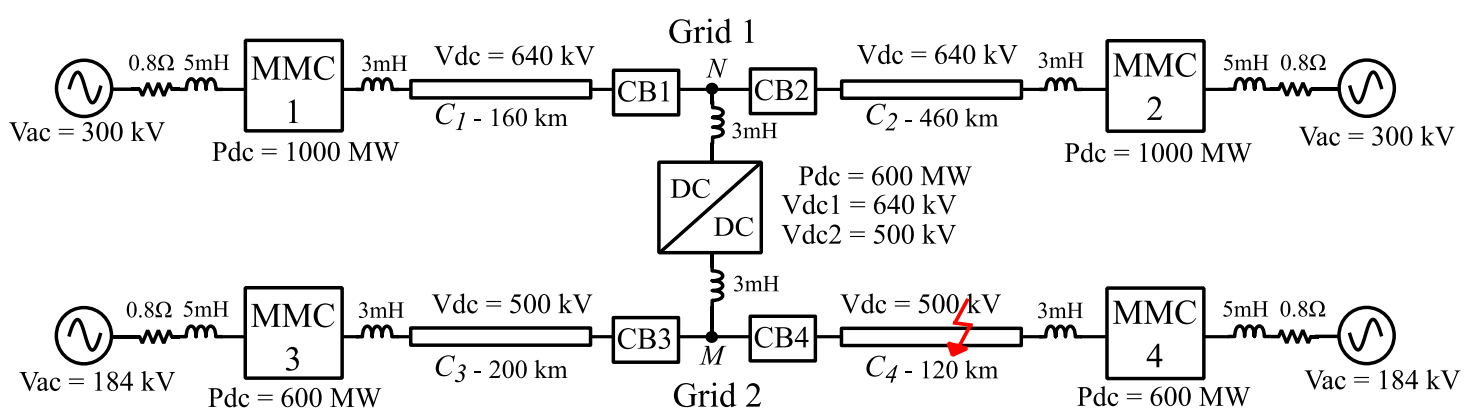

Figure 1: Case study with the studied fault location

inserted. In the same node is also connected the first terminal of the DC-DC converter.

Grid 2 has a similar configuration, it is an asymmetrical monopole of $+500 \mathrm{kV}$ formed by stations MMC3 and MMC4, cables $\mathrm{C} 3$ and $\mathrm{C} 4$, circuit breakers $\mathrm{CB} 3$ and $\mathrm{CB} 4$, and the second terminal of the DC-DC converter (node $\mathrm{M}$ ).

The system is studied under normal and fault conditions. The study focus on pole-to-ground faults which is the most common type of faults in HVDC cables. The analysis is done for asymmetrical monopoles. The results are also representative of a pole-to-ground fault in bipolar systems.

The CBs are added to isolate the faulty cable from the healthy portion of the grid and to demonstrate the system recovery after the fault. However they are not indispensable for the proposed DC- DC converter control method under faults, which is the purpose of the paper.

Concerning the control of the grid, a simple control strategy is implemented: stations MMC1 and MMC3 control the DC voltage of each sub-grid, while the DC-DC converter and stations MMC2 and MMC4 control the power flow.

\subsection{Converter, cable and CB Models}

The implemented DC-DC converter uses the F2F-MMC as shown in Figure 2. The MMCs of the structure, as well as each MMC station at the end of each line, are built with half-bridge (HB) submodules (SMs).

Figure 3 presents the converter average model used in this study. Each MMC SM stack is replaced by a controlled voltage source. The energy stored in the SM capacitors is modelled with an equivalent capacitor and a current source to represent its charge/discharge. An antiparallel diode and one IGBT are

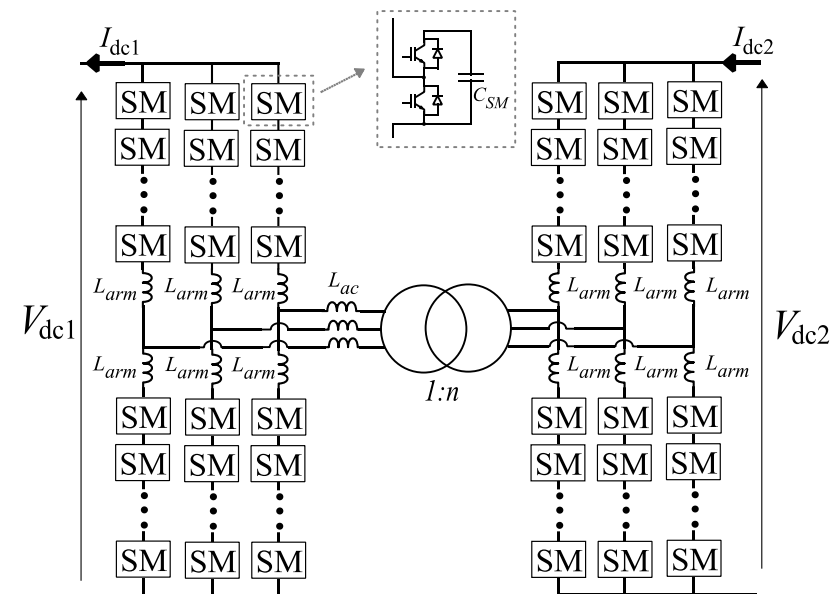

Figure 2: F2F-MMC added to model the behaviour of the converter in the blocked state [8]. The converter parameters are presented in Table 1.

Each cable is modelled using a 10 section $\pi$-model. The model includes parallel branches of inductors and resistors to represent the impedance variation in function of the frequency [9]. The model parameters are calculated to fit the cable impedance with the DC characteristics of Table 1 taking into account the skin effect until $1 \mathrm{kHz}$ [10]. Each circuit breaker is modelled as proposed in [11].

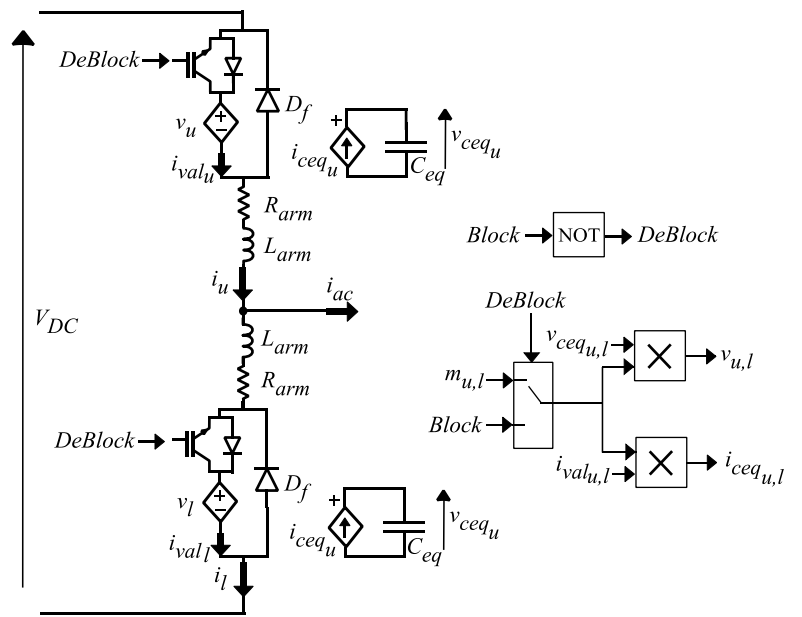

Figure 3: Average model of one of the three MMC arms [8].

\section{Converter control}

\subsection{MMC control}

MMC operation requires to control the arm currents and the $\mathrm{SM}$ capacitor voltages to keep them within a safe range. One approach is to have several nested control loops separating AC and DC side currents control and controlling the capacitor voltages with an energy controller [12]. The implemented MMC control scheme is presented in Figure 4. The DC current and energy controllers are implemented per converter phase, while the AC current control is done in dq frame.

Current control loops are the most internal loops having the fastest dynamics. Instead of controlling the arm currents directly, the DC and AC components are controlled. To obtain the DC and AC side quantities from the arm currents, a variable change is done as given by Equation (1) and Equation (2).

$$
\begin{aligned}
& {\left[\begin{array}{c}
i_{\text {diff }_{i}} \\
i_{a c_{i}}
\end{array}\right]=\left[\begin{array}{cc}
0.5 & 0.5 \\
1 & -1
\end{array}\right]\left[\begin{array}{l}
i_{u_{i}} \\
i_{l_{i}}
\end{array}\right]} \\
& i_{\text {diff }_{i}}=\frac{I_{D C}}{3}+i_{\text {circ }_{i}}
\end{aligned}
$$




\begin{tabular}{|c|c|c|c|c|}
\hline Parameter & $\begin{array}{c}F 2 F \\
\text { Node } \\
N\end{array}$ & $\begin{array}{c}F 2 F \\
\text { Node } \\
M\end{array}$ & $\begin{array}{l}M M C 1 \\
M M C 2 \\
M M C 3 \\
M M C 4\end{array}$ & $\begin{array}{c}\text { Cables } \\
\text { C1,C2, } \\
\text { C3, C4 }\end{array}$ \\
\hline SM Capacitor $\left(\mathrm{C}_{S M}\right)$ & $2.5 \mathrm{mF}$ & $3.2 \mathrm{mF}$ & $10 \mathrm{mF}$ & - \\
\hline SMs per arm (\#SMs) & 400 & 313 & 400 & - \\
\hline $\begin{array}{l}\text { Equivalent Capacitor } \\
\text { (Ceq= } \mathrm{C}_{S M} / \# \mathrm{SMs} \text { ) }\end{array}$ & $6.2 \mu \mathrm{F}$ & $10.2 \mu \mathrm{F}$ & $25 \mu \mathrm{F}$ & - \\
\hline $\operatorname{Arm}$ inductor $\left(L_{\text {arm }}\right)$ & $14 \mathrm{mH}$ & $8.4 \mathrm{mH}$ & $50 \mathrm{mH}$ & - \\
\hline Arm resistance $\left(R_{\text {arm }}\right)$ & $0.51 \Omega$ & $0.25 \Omega$ & $1 \Omega$ & \\
\hline AC bus inductor & \multicolumn{2}{|c|}{$40 \mathrm{mH}$} & - & - \\
\hline Transformer ratio $(n)$ & \multicolumn{2}{|c|}{0.78} & - & - \\
\hline AC Frequency & $350 \mathrm{~Hz}$ & $350 \mathrm{~Hz}$ & $50 \mathrm{~Hz}$ & - \\
\hline Cable DC Resistance & - & - & - & $5.3 \mathrm{~m} \Omega / \mathrm{km}$ \\
\hline Cable DC Inductance & - & - & - & $2.9 \mathrm{mH} / \mathrm{km}$ \\
\hline Cable DC Capacitance & - & - & - & $242 \mathrm{nF} / \mathrm{km}$ \\
\hline
\end{tabular}

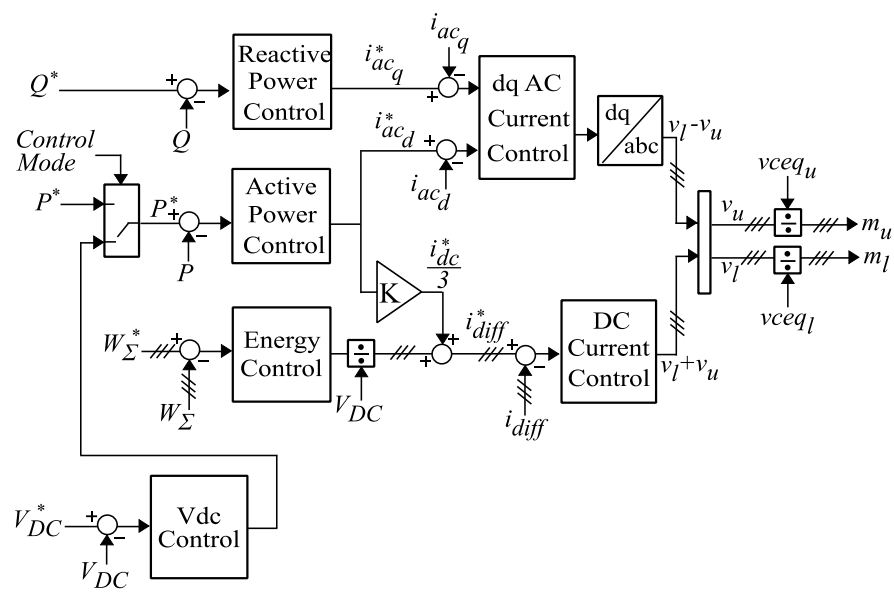

Table 1: Converter and cable parameters

For explanation purposes along the paper, the circulating current between arms $i_{\text {circ }}$ will be ignored and it will be assumed that $i_{\text {diff }}$ is composed only by its DC component.

The current references are given by a power and an energy controller. The DC current dynamics is given by Equation (3). This current can be controlled by the addition of the voltages generated by both same-leg arms, i.e. $v_{u_{i}}+v_{l_{i}}$.

$\frac{d i_{d i f f}}{d t}=-\frac{R_{a r m}}{L_{a r m}} i_{\text {diff } f_{i}}-\frac{1}{2 L_{\text {arm }}}\left(v_{u_{i}}+v_{l_{i}}\right)+\frac{1}{2 L_{\text {arm }}} v_{d c}$

The AC current dynamics is given by Equation (4). This current is controlled by the difference of the voltages generated by both arms, i.e. $v_{l_{i}}-v_{u_{i}}$, being $v_{a c_{i}}$ the AC grid voltage. Since the MMC is a three phase AC system, a d-q frame based control is used.

$\frac{d i_{a c_{i}}}{d t}=-\frac{R_{a r m}+2 R_{a c}}{L_{a r m}+2 L_{a c}} i_{a c_{i}}+\frac{2}{L_{a r m}+2 L_{a c}}\left(\frac{\left(v_{l_{i}}-v_{u_{i}}\right)}{2}-v_{a c_{i}}\right)$

The power controller set-point depends on the MMC control mode, controlling grid DC voltage or power transfer. The energy controller reference is internal to the converter and it is constant to set the capacitor voltages to the nominal value, i.e. the nominal DC voltage of the DC side.

The energy loop controls the total stored energy in each leg and the difference of the energy in upper and lower arms. This control is implemented using the proposed approach in [13].

The stored energy in one leg is given by Equation (5) and its dynamics by Equation (6). This equation shows that it varies if there is a difference between the AC and DC powers. Both powers are normally balanced, however during transients an additional power should be absorbed by the converter. This exceeding power is the output of the energy controller, and will be added to the DC current reference as shown in Figure 4.

$$
\begin{aligned}
W_{\Sigma_{i}} & =\frac{1}{2} C_{e q}\left(\left(v_{c e q_{u_{i}}}\right)^{2}+\left(v_{c e q_{l_{i}}}\right)^{2}\right) \\
\frac{d W_{\Sigma_{i}}}{d t} & =i_{d i f f_{i}} v_{d c}-v_{a c_{i}} i_{a c_{i}}=\frac{P_{d c}}{3}-\frac{P_{a c}}{3}
\end{aligned}
$$

For the stations controlling DC grid voltage, a DC voltage control loop is added. The dynamics of the DC voltage is given by Equation (7). Where $C_{d c}$ represents the aggregated capacitance of the cables in the grid and $P_{\text {grid }}$ the power being

Figure 4: MMC Control Scheme.

exchanged in other grid terminals. To control the DC voltage, the MMC must change its power reference.

$$
\frac{1}{2} C_{d c} \frac{d v_{d c}^{2}}{d t}=P_{\text {grid }}-P_{M M C}
$$

All controllers are implemented with PI controllers, tuning the time response of each internal loop (current loops) to be faster than the external loops (Energy and DC voltage loops).

\subsection{F2F-MMC control}

Controlling the F2F-MMC requires to control two MMCs. The internal energy and DC current of each MMC are controlled using the controller explained in the previous section. However the AC current control differs because in this case there is not any external AC grid, it should be created inside the converter. The simplest way to control the AC bus is that one MMC fixes the $\mathrm{AC}$ voltage in open loop using the difference of the voltages

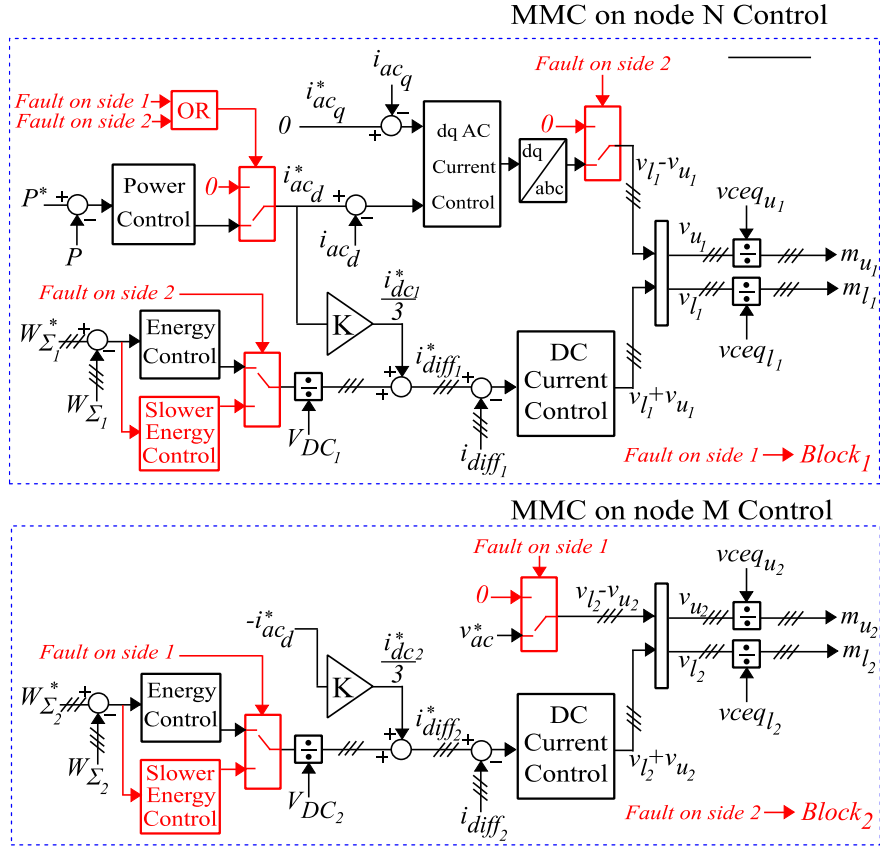

Figure 5: F2F-MMC Control Scheme. The blocks highlighted in red correspond to the converter control under DC grid faults. 
generated by its arms, i.e. $v_{l_{i}}-v_{u_{i}}$, while the second MMC controls the power flow.

The F2F-MMC control scheme is presented in Figure 5. MMC on node $\mathrm{M}$ sets the internal AC voltage, while MMC connected to node $\mathrm{N}$ assures the power transfer controlling the $\mathrm{AC}$ current. No DC grid voltage controller is implemented for the F2F-MMC because it is being controlled by stations MMC1 and $\mathrm{MMC} 3$.

\subsection{Normal operation simulation results}

To validate the converter control, a simulation of the system without faults is made. The study is done in Matlab/Simulink with SimscapePowerSystems toolbox. The results are presented in Figure 6. MMC1 and MMC3 control the DC grid voltages, while different power references are given to stations MMC2, MMC4 and the DC-DC converter.

It is observed that the grid voltage is effectively controlled and that the energy on the stations is kept at nominal values changing only when there are power fluctuations. The stored energy on the F2F-MMC is less than the energy stored in the other stations given the smaller SM capacitance required, as presented in Table 1, due to the medium frequency (MF) operation.

\section{Proposed control under faults}

When a fault occurs on the DC grid, the voltage collapses and high currents are generated due to the discharge of the cable and converter capacitors. To protect the converter stations, the converters are blocked when an overcurrent is detected. When blocked, the HB based MMC behaves like a diode rectifier, and the fault current is continuously fed by the $\mathrm{AC}$ grid if no circuit breaker (AC or DC) is opened to isolate the fault.

In the case of the F2F-MMC, the fault is stopped if both MMCs are blocked [4], [6]. However the healthy DC grid experiences a voltage dip/swell caused by the abrupt power loss from/to the DC-DC converter. To decrease this perturbation, this paper proposes to block only the MMC that is connected to the faulty grid and to use the unblocked MMC to control the healthy side DC current.

The proposed control is highlighted in Figure 5. In the F2FMMC, the unblocked MMC decreases its AC voltage output to zero in order to avoid any contribution of the DC-DC converter to the fault current on the faulty side. So the blocked MMC behaving as an uncontrolled rectifier does not have an AC grid from where it can supply the fault.

To avoid the voltage perturbation on the healthy side, the DCDC converter must be capable of maintaining the power flow as before the fault. This is not possible because the converter cannot inject/absorb all this power to/from the faulty grid. The power unbalance (very low power on faulty side, given the low voltage caused by the fault, and operating power on healthy side) causes a variation on the converter energy. To keep the energy around the nominal value, the converter energy controller will decrease the DC current reference towards zero. Depending on how fast this current is decreased, the perturbation on the grid will be more important. Then, slowing down the controller response, the perturbation on the DC grid can be decreased. It should be noted that the time response should not be excessively slow because the capacitors will then discharge under the minimal operation voltage (50\% when no $\mathrm{AC}$ voltage is generated on the converter), or exceed the maximum voltage rating. Then the maximum achievable time response depends on the installed capacitance.

\subsection{DC fault simulation results}

To validate the proposed control scheme, a pole-to-ground fault is generated on cable $\mathrm{C} 4$ at $60 \mathrm{~km}$ from station MMC4. The power flow before the fault was set to $600 \mathrm{MW}$ for MMC2, $200 \mathrm{MW}$ for MMC4 and $400 \mathrm{MW}$ for the F2F-MMC. Converters MMC1 and MMC3 control the DC grid voltages. When the fault occurs MMC3 and MMC4 will be blocked, a trip order to open CB4 is sent, and the F2F-MMC enters in fault control mode. The $\mathrm{CB}$ trip signal is generated measuring the difference of current on both cable ends and comparing with a threshold value. The trigger signal to change the control mode on the F2F-MMC is given when the arm currents double the nominal value, or when the DC voltage drops below $90 \%$ of the nominal voltage. After $50 \mathrm{~ms}$ from CB4 opening, MMC3 is unblocked to reenergize $\mathrm{C} 3$ cable. This time was assumed since the coordination of CB4 and MMC3 unblocking is out of the scope of this paper. Because the F2F-MMC experienced a variation of its energy during the fault, it remains in fault control mode until the arm energy comes back to the nominal value. Then the converter control passes to normal operation mode and the system power flow is re-established.

Simulation results are presented in Figure 7. The effectiveness of using DC-DC converters as firewalls against faults is
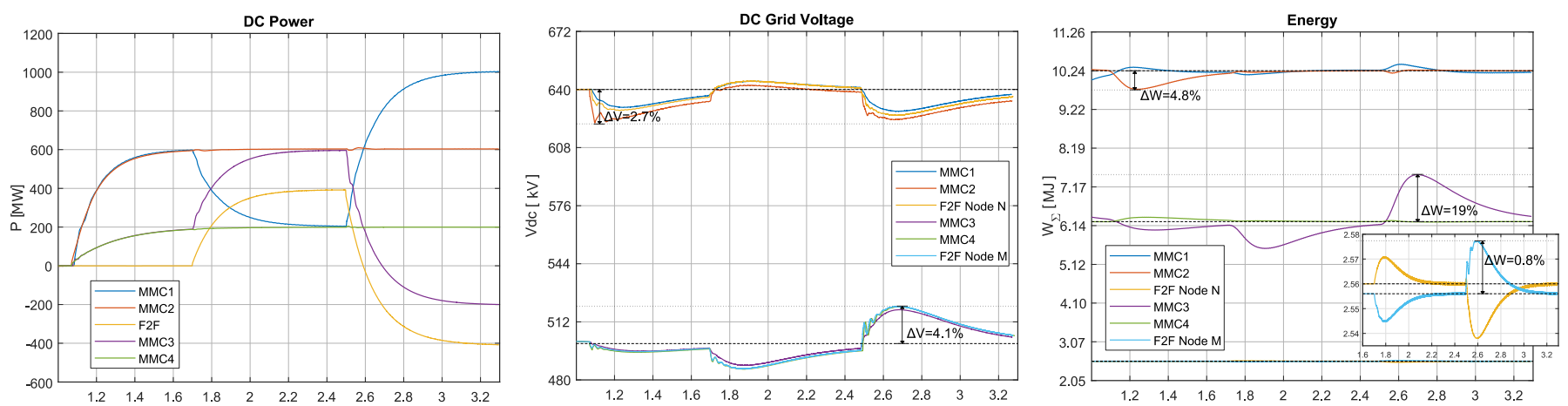

Figure 6: Normal scenario simulation results. DC power and voltages are measured on converter terminals. The presented energy is the total energy in one converter leg. 

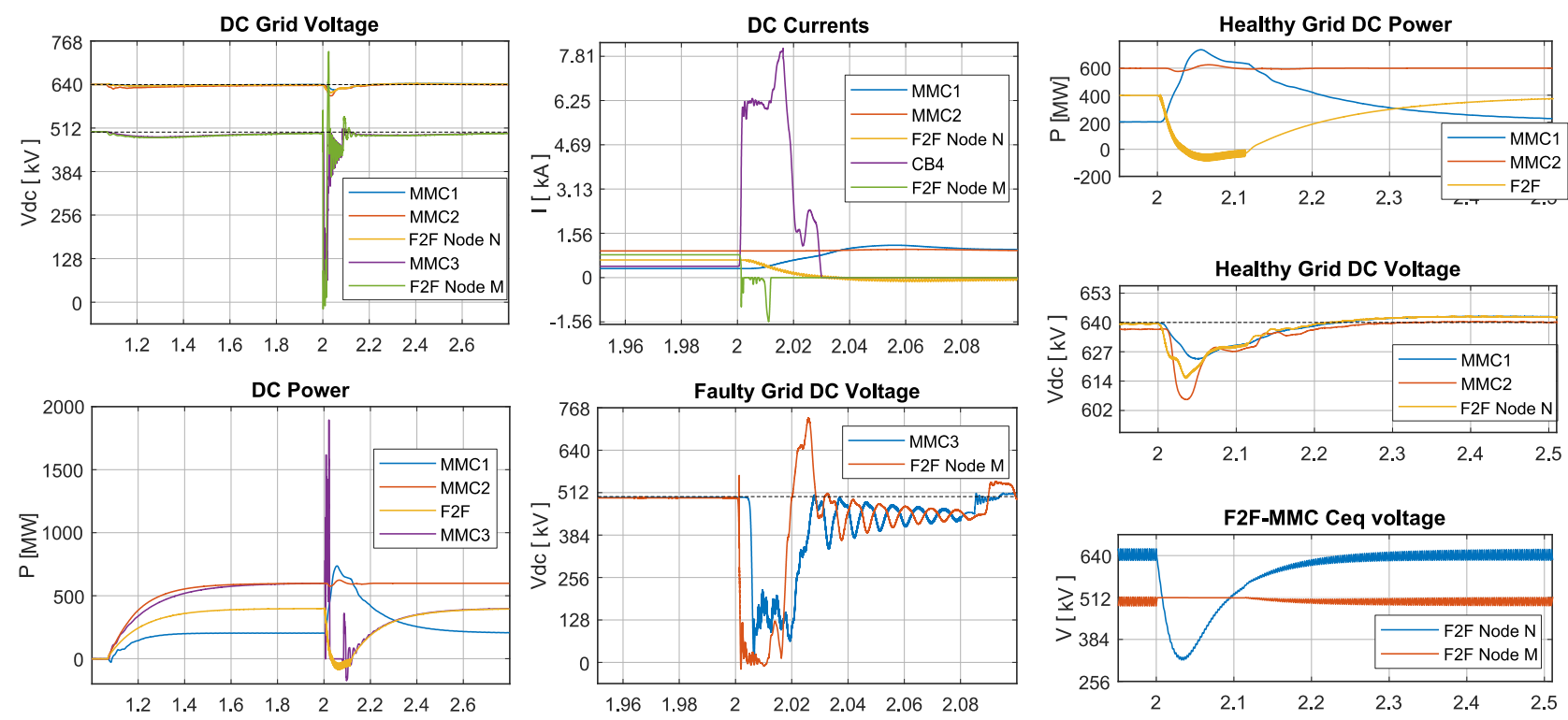

Figure 7: Fault scenario simulation results. DC powers and voltages are measured on converter terminals. The voltage on equivalent capacitor that is presented is only for the upper arm of one converter leg.

confirmed. When the fault occurs, it does not propagate to the healthy grid which only experiences a voltage dip.

Observing the currents on the faulty grid, (CB4 and F2F Node $\mathrm{M}$ currents) it is seen that the F2F-MMC only contributes to the fault current before the MMC on node $\mathrm{M}$ is blocked. Once the converter is blocked, the DC current contribution is zero. The negative peaks on the current are caused by the DC grid voltage oscillations during fault that reaches negative values, then the freewheeling diodes $\left(D_{f}\right.$ on Figure 3$)$ on the blocked

Regarding the healthy grid, thanks to the proposed control, the DC power flowing from the DC-DC converter decreases smoothly to zero after the fault. A DC voltage dip of 5\% $(32 \mathrm{kV})$ is obtained. During this transient the capacitors of the unblocked MMC are discharged down to the minimal operation point $(320 \mathrm{kV})$. If a slower transition is required, the controller response can be slowed-down if more capacitance is installed, then the capacitors discharge takes more time to MMCs are forward biased.
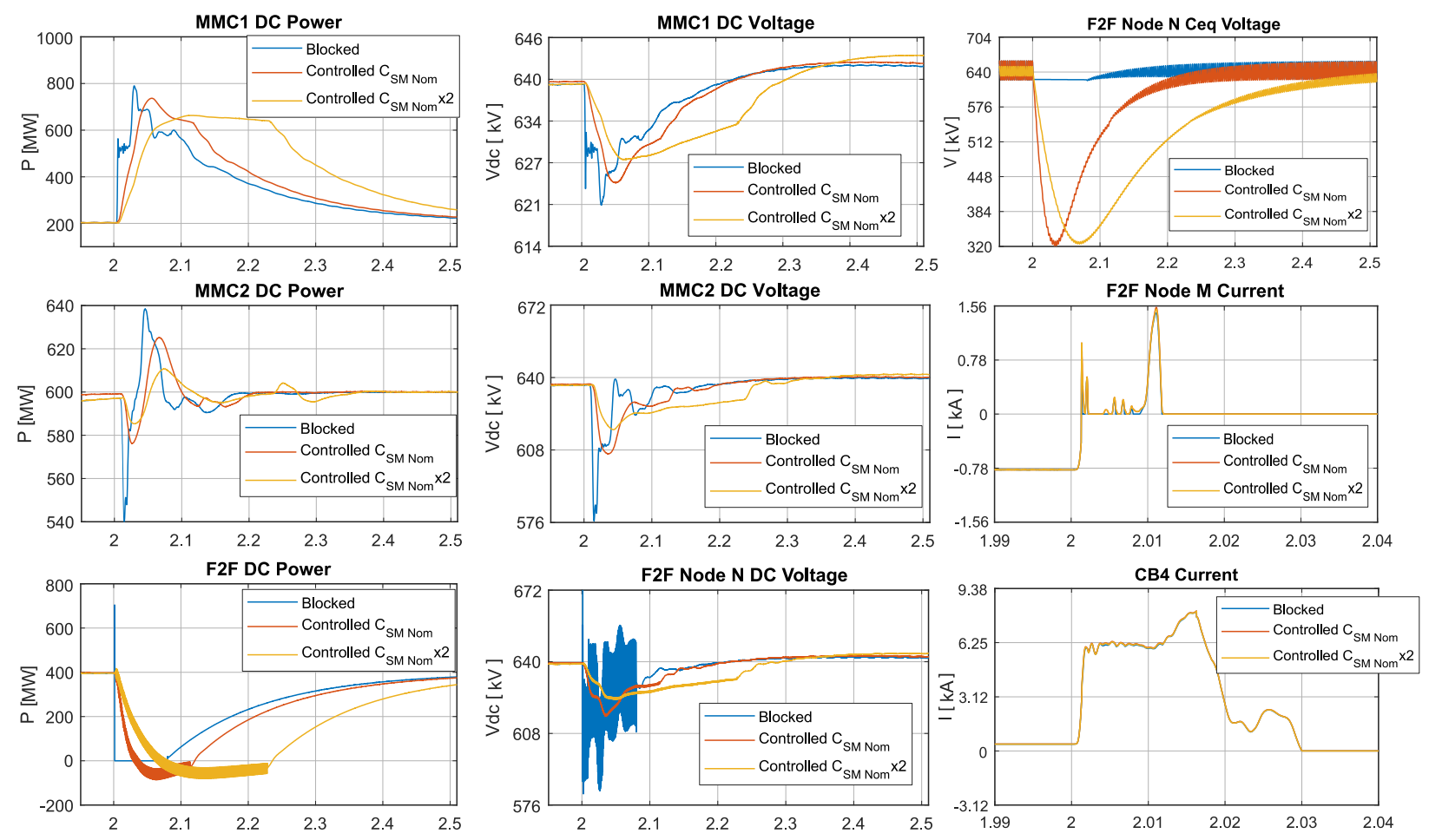

Figure 8: Comparison of fault scenario simulation results for the proposed control method with two different DC-DC converter installed capacitances and when blocking the converter. DC power and voltages are measured on converter terminals. The presented voltage on F2F-MMC equivalent capacitor is only for the upper arm of one converter leg. 
In Figure 8, the behaviour of the proposed control is compared with the case of blocking both F2F-MMC sides and also with the proposed control when the installed capacitance is doubled (controller time response is set to a slower value).

If the DC-DC converter is totally blocked, the perturbations on the healthy grid are more important, particularly for the power on station MMC1 that changes abruptly $(22 \mathrm{GW} / \mathrm{s})$ to keep the DC voltage controlled. With the proposed method the MMC1 power variation is smoothed $(11 \mathrm{GW} / \mathrm{s}$, and to $6 \mathrm{GW} / \mathrm{s}$ when doubling the DC-DC converter installed capacitance). The power flow on station MMC2 is less affected than in MMC1, but is also smoothed with the proposed control.

Comparing the voltage dip in MMC1 station, the perturbation magnitude is not so different in the three cases, this is because this station is in DC voltage control mode. However for station MMC2 the voltage dip is decreased from $10 \%$ to $5 \%$ with the proposed control and to $3 \%$ when doubling the installed converter capacitance.

The effect of decreasing the perturbation on the healthy subgrid comes at the cost of retarding the power flow recovery. Indeed even if CB4 opens fast isolating the fault and MMC3 unblocks to set Grid 2 operational, the F2F-MMC cannot transmit power until the capacitor voltages came back to their nominal value.

Concerning the faulty side, it is observed that the proposed method does not affect the fault current. In all the three cases the DC-DC converter has the same contribution to the fault current, i.e. until MMC on node $\mathrm{M}$ is blocked.

\section{Conclusions}

The study of a DC-DC converter in a multi-terminal DC grid was presented. It is presented that such an element adds flexibility to the power flow, for example both ends of a P2P link can absorb/deliver power at the same time.

The role of DC-DC converters in a DC grid protection strategy based on grid partitioning was studied. The behaviour of such circuits as firewalls was confirmed. However it has been seen that even if the fault is stopped, a perturbation on the healthy sub-grid is generated. A DC-DC converter control method was proposed to decrease this perturbation when a fault occurs.

The proposed method was analysed for two different values of installed converter capacitance. It was observed that the internal stored energy can have an effect on the grid behaviour. With the present study it is concluded that DC-DC converters can integrate additional functionality of interest for a DC grid operation to just performing a DC voltage transformation.

\section{Acknowledgements}

This work was supported by a grant overseen by the French National Research Agency (ANR) as part of the "Investissements d'Avenir" Program ANE-ITE-002-01.

\section{References}

[1] D. Jovcic, D. Van Hertem, K. Linden, J.-P. Taisne, and W. Grieshaber, "Feasibility of DC transmission networks," in Innovative Smart Grid Technologies
(ISGT Europe), 2011 2nd IEEE PES International Conference and Exhibition on, 2011, pp. 1-8.

[2] PROMOTioNProject, "D4.2 - Broad comparison of fault clearing strategies for DC grids," PROMOTioN, 2017.

[3] J. D. Paez, D. Frey, J. Maneiro, S. Bacha, and P. Dworakowski, "Overview of DC-DC Converters dedicated to HVDC Grids," IEEE Transactions on Power Delivery, 2018.

[4] I. Gowaid, G. Adam, A. M. Massoud, S. Ahmed, D. Holliday, and B. Williams, "Quasi two-level operation of modular multilevel converter for use in a high-power DC transformer with DC fault isolation capability," IEEE Transactions on Power Electronics, vol. 30, no. 1, pp. 108-123, 2015.

[5] R. Li, L. Xu, L. Yao, and B. W. Williams, "Active Control of DC Fault Currents in DC Solid-State Transformers During Ride-Through Operation of Multi-Terminal HVDC Systems," IEEE Transactions on Energy Conversion, vol. 31, no. 4, pp. 1336-1346, Dec. 2016.

[6] M. H. Rahman, L. Xu, and L. Yao, "DC fault protection strategy considering DC network partition," in Power and Energy Society General Meeting (PESGM), 2016, 2016, pp. 1-5.

[7] S. Kenzelmann, A. Rufer, D. Dujic, F. Canales, and Y. R. De Novaes, "Isolated DC/DC structure based on modular multilevel converter," IEEE Transactions on Power Electronics, vol. 30, no. 1, pp. 89-98, 2015.

[8] H. Zhang, D. Jovcic, W. Lin, and A. J. Far, "Average value MMC model with accurate blocked state and cell charging/discharging dynamics," in Environment Friendly Energies and Applications (EFEA), 2016 4th International Symposium on, 2016, pp. 1-6.

[9] B. K. Sen and R. L. Wheeler, "Skin effects models for transmission line structures using generic SPICE circuit simulators," in IEEE 7th Topical Meeting on Electrical Performance of Electronic Packaging (Cat. No.98TH8370), 1998, pp. 128-131.

[10] C. Stackler, F. Morel, P. Ladoux, and P. Dworakowski, " $25 \mathrm{kV}-50 \mathrm{~Hz}$ railway supply modelling for medium frequencies (0-5 kHz)," in Electrical Systems for Aircraft, Railway, Ship Propulsion and Road Vehicles \& International Transportation Electrification Conference (ESARS-ITEC), International Conference on, 2016, pp. 1-6.

[11] PROMOTioNProject, "D6.2. - Develop system level model for mechanical DCCB," PROMOTioN, 2016.

[12] A. Zama, A. Benchaib, S. Bacha, D. Frey, and S. Silvant, "High dynamics control for MMC based on exact discrete-time model with experimental validation," IEEE Transactions on Power Delivery, 2017.

[13] K. Shinoda, J. Freytes, A. Benchaib, J. Dai, H. Saad, and X. Guillaud., "Energy Difference Controllers for MMC without DC Current Perturbations.," in The 2nd International Conference on HVDC(HVDC2016), Sep 2016, Shanghai, China. eProceedings of HVDC 2016, 2016. 